\title{
UTILIZAÇÃO DE VÍDEO EDUCATIVO SOBRE CLONAGEM NO ENSINO DE CIÊNCIAS
}

\author{
USING EDUCATIONAL VÍDEO ON CLONING IN SCIENCE TEACHING
}

\author{
Claudiene Rafalski ${ }^{1}$, Silvânia Alves Martins², Kátia Liége Nunes Gonçalves ${ }^{3}$, Alessandra de \\ Rezende Ramos ${ }^{4}$
}

Recebido: julho/2019 Aprovado: agosto/2021

\begin{abstract}
Resumo: $O$ estudo foi idealizado com objetivo de popularizar um tema científico-tecnológico atual, a clonagem, utilizando para isso recursos multimídias como ferramenta pedagógica, em função da fácil aceitação entre os alunos. A produção do vídeo foi realizada em três etapas: 1) levantamento de mídias disponíveis na internet sobre clonagem, 2) roteiro e filmagem do curta-metragem e 3) edição do vídeo que teve duração de dez minutos. A análise do vídeo foi qualitativa, por meio de questionários, sendo um instrumento aplicado aos graduandos do Curso de Licenciatura em Ciências Naturais da UNIFESSPA, e dois aos estudantes do nono ano do Ensino Fundamental, de uma Escola Pública do Município de Marabá/PA. O uso do vídeo apontou como contribuições: a) o entendimento do processo de clonagem, de forma lúdica e dinâmica e b) a adoção de vídeos 'caseiros' como ferramenta didático-pedagógica, de fácil produção e baixo custo, motivou os estudantes no processo de ensino e aprendizagem de ciências

Palavras-chave: Ferramenta didático-pedagógica, Mídia-educação, Educação Básica.

Abstract: The study was designed to popularize a current scientific-technological theme, cloning, using multimedia resources as a pedagogical tool, due to the easy acceptance among students. The video production was carried out in three stages: 1) survey of media available on the internet on cloning, 2) script and filming of the short film, and 3) editing the video, which lasted ten minutes. The video analysis was qualitative, through questionnaires, being an instrument applied to the undergraduate students in the Natural Sciences Degree Course at UNIFESSPA, and two to students in the ninth grade of Elementary Education, from a Public School in the Municipality of Marabá / PA. The use of the video pointed out as contributions: a) the understanding of the cloning process, in a fun and dynamic way and b) the adoption of 'home' videos as a didactic-pedagogical tool, of easy production and low cost, motivated the students in the process of science teaching and learning
\end{abstract}

Keywords: Didactic and pedagogical tools, Multimedia resources, Elementary school.

\section{Introdução}

O uso dos recursos midiáticos, em especial o vídeo, em ambiente educativo possibilita o acordar da criatividade e estimula a construção de aprendizados variados, em concordância com a exploração da suscetibilidade e das emoções dos estudantes, além de contextualizar diversos conteúdos descritos no currículo escolarizado. A partir desse conjunto de possibilidades, o

\footnotetext{
${ }^{1}$ Mestrado em Agronomia, UFPB. Rodovia PB 079, Km 12, Areia, Paraíba, Brazil, 58.397-000. E-mail: ninarafalski@hotmail.com

${ }^{2}$ Mestrado em Agronomia, UFPB. Rodovia PB 079, km 12, 58397-000, Areia-PB, Brasil. E-mail: silvania20alves@hotmail.com

${ }^{3}$ Doutorado Educação Matemática, UFPA. Docente, Faculdade de Matemática, UFPA, Castanhal, Pará, Brasil. Av. dos Universitários, s/n Jaderlândia, 68746630 - Castanhal, Pará, Brasil. E-mail: liegekatia@ufpa.br

4 iD 0000-0001-9566-4333 - Doutorado em Genética e Biologia Molecular, UFPA. Docente PPGECM/Unifesspa, Marabá, Pará, Brasil. Avenida dos Ipês s/n, Cidade Jardim, Marabá, Pará, Brazil, 68.500-000. E-mail: rezende@unifesspa.edu.br
} 
docente pode conduzir o estudante a aprendizados significativos que fomentem princípios de cidadania e de ética (SILVA; MERCADO, 2010).

Desde a década de cinquenta já existe uma preocupação com a mídia em contexto educativo, especialmente com relação à propaganda. Neste período apareceram as expressões: "educação para as mídias" ou "mídia-educação" mencionadas primeiramente pela UNESCO. Em 1962 teve início o movimento para a utilização da mídia-educação como ferramenta pedagógica para os docentes. Nesse período houve a aprovação da Declaração de Grünwald, durante o Simpósio Internacional de Educação em Mídia, em Grünwald, Alemanha Ocidental. A declaração chama atenção para a importância das mídias, e do compromisso dos sistemas educacionais de auxiliarem os cidadãos na melhor compreensão destas ferramentas (UNESCO, 1982; BÉVORT; BELLONI, 2009; DUDZIAK; FERREIRA; FERRARI, 2017).

No final do século vinte, com o crescente progresso televisivo e a chegada da internet, as Tecnologias de Informação e Comunicação (TIC) trouxeram à sociedade novas possibilidades de comunicação mais interativas, além da produção e difusão de informações de forma dinâmica, inimagináveis aos que nasceram no século passado. O conjunto das chamadas 'indústrias culturais' (rádio, cinema, televisão, impressos) vivencia uma mutação tecnológica sem precedentes com a digitalização que, embora longe de ter esgotado seus efeitos, já delineava uma nova paisagem comunicacional e informacional (BÉVORT; BELLONI, 2009). Entende-se como TIC as mídias do tipo: televisão e suas variantes (videocassete, DVD, antena aberta e por assinatura), jogos de vídeo (videogames) e de computador, máquinas fotográficas e filmadoras de vídeo, Ipod, MP3, telefones celulares e redes mídias interativas (multimídias) (BÉVORT; BELLONI, 2009; TUFTE; CHRISTENSEN, 2009).

No mundo atual globalizado e em constante transformação, muitos avanços científicos e tecnológicos chegam até nós todos os dias por diversos meios de comunicação sejam eles televisivos, jornais impressos, revistas, internet; e apresentam assuntos intrigantes como: nanotecnologia, transgênicos, sequenciamento de genomas, terapia gênica, clonagem, teste de paternidade, entre outros (NUNES, 2010; OLIVEIRA; DIAS JUNIOR, 2012).

Diante da visibilidade destes assuntos intrigantes e em evidência, o tema clonagem foi escolhido para ser trabalhado, uma vez que foi previamente relatado o interesse para esse assunto entre estudantes do 9o ano do Ensino Fundamental de uma Escola Pública do Município de Novo Progresso/PA (dados não publicados). Assuntos desta natureza podem instigar a curiosidade dos estudantes, assim como fornecer ao docente um campo fértil de possibilidades de investimento educativo, previstos pela Base Nacional Comum Curricular (BNCC), e que nem sempre são encontrados nos capítulos de livros utilizados no Ensino Fundamental, mas que estão contidos nos Temas Transversais, que junto com as disciplinas específicas, quando bem articulados, apresentam uma relação fundamentalmente complementar que transpassa os conteúdos específicos das disciplinas (CARNEIRO; FARIA; CHUVARTZ, 2009; MOUSINHO, 2018; PENHA; MACIEL, 2021).

A temática clonagem foi escolhida, pois além de provocadora, comportava questionamentos ético-religiosos, que necessitavam de esclarecimentos, de modo a desmistificar um assunto ainda em destaque. Ademais, a evidência de temas biotecnológicos abordados diariamente nos meios de comunicação, reforça a necessidade destes também 
serem trabalhados nas escolas, de maneira mais dinâmica e interacionista, uma vez que vivemos em sociedade globalizada. Por isso entendemos que essa democratização da Ciência e Tecnologia necessita iniciar no ambiente escolar.

Define-se clonagem como um mecanismo comum de propagação encontrada em plantas, fungos e bactérias. Em humanos, os gêmeos idênticos são considerados clones naturais, pois se originam da divisão de um mesmo óvulo fertilizado. Desde o anúncio do nascimento da ovelha Dolly, o assunto clonagem não abandonou mais a mídia e abriu caminho para a polêmica sobre a possibilidade de clonagem humana, uma vez que foi possível clonar um mamífero (ZATZ, 2002; 2004), e recentemente cientistas chineses já produziram macacos utilizando esta técnica (LIU et al., 2018), fato que causa impacto e suscita questionamentos na própria comunidade acadêmica. Contudo é importante reforçar a diferença entre a clonagem reprodutiva, que tem por finalidade formar seres geneticamente idênticos; e a clonagem terapêutica, que visa a formação de tecidos ou órgãos para transplantes (SILVA, 2004).

Considerando a popularização destes recursos midiáticos, sua fácil aceitação entre os estudantes, e a temática envolvida para o ensino de Ciências, o presente trabalho teve como objetivo principal a produção de um vídeo educativo sobre Clonagem, que abordasse o tema de forma lúdica e concisa; e como objetivos secundários a avaliação deste vídeo entre os alunos do Ensino Superior (ES) e Ensino Fundamental (EF), visando sua utilização nas aulas de Ciências, para promover aprendizagens mais interativas e significativas. Esta pesquisa apresentou uma avaliação qualitativa, dos questionários avaliativos respondidos pelos alunos do ES e EF que assistiram o vídeo, na perspectiva da análise textual discursiva (MORAES, 2003; MORAES; GALIAZZI, 2007).

\section{Metodologia}

Pesquisa qualitativa de caráter exploratório, do tipo descritiva, aplicada no propósito de levantar os sentidos atribuídos à avaliação do vídeo educativo sobre clonagem, apresentada pelos alunos do ES e EF, na cidade de Marabá/Pará.

Para o desenvolvimento desta pesquisa foi adotado o uso dos Questionários Avaliativos, como instrumentos de coleta de dados, sendo aplicado um instrumento para os alunos do ES (QA1) e dois para os alunos do EF (QA2 e QA3). A Análise Textual Discursiva (MORAES, 2003; MORAES; GALIAZZI, 2007) foi utilizada como ferramenta analítica, pois baseia-se na produção de novas compreensões sobre os fenômenos e discursos, considerando o contexto de quem fala (MORAES; GALIAZZI, 2011).

A Análise Textual Discursiva consiste em um processo rigoroso, sistemático e não neutro, e sua organização pode ser compreendida em três etapas: 1) Unitarização: refere-se à seleção de unidades de sentido do material de estudo ou corpus textual, a qual ocorre por meio da desmontagem dos textos; 2) Categorização: busca estabelecer relações entre as unidades obtidas do corpus em categorias analíticas, seja por categorias definidas a priori, por um referencial teórico, e/ou durante a realização da análise; 3) Metatexto: constitui na expressão das novas compressões obtidas por meio da reorganização das unidades nas categorias, pautado no foco da captação do novo emergente (MORAES; GALIAZZI, 2011). 
O vídeo educativo foi idealizado a partir de uma proposta avaliativa, de caráter extensionista, na disciplina de Biotecnologia e o Homem, da matriz curricular do curso de Licenciatura Plena em Ciências Naturais, da Universidade Federal do Sul e Sudeste do Pará (UNIFESSPA). A temática escolhida foi baseada em uma pesquisa anterior, com alunos do EF, que demonstraram dúvidas e interesse sobre o tema (dados não publicados). A produção ocorreu em três etapas. Na primeira etapa houve o levantamento das mídias disponíveis na internet (animações, vídeos, documentários, filmes) sobre o tema clonagem. Na segunda etapa foi elaborado um roteiro inédito, que abordava: o que é clonagem; qual a diferença entre clonagem reprodutiva e clonagem terapêutica, e quais são os riscos e os benefícios nos dois procedimentos; os primeiros mamíferos clonados, a ovelha Dolly (CAMPBELL et al., 1996) e a bezerra Vitória, primeiro animal clonado na América Latina (RUMPF; IGUMA; SOUSA, 2001) e clonagem em humanos. Para a filmagem do curta-metragem foi utilizado um notebook CCE modelo 745B. A última etapa constou da edição do vídeo, utilizando o software Movie Maker (WMM), da Microsoft, que integra o sistema operacional Windows. A duração total do vídeo foi de dez minutos.

O vídeo foi exibido no ano de 2014, a dez (10) alunos do sexto período, que faziam a disciplina de Biotecnologia e o Homem. Após a exibição do curta foi aplicado um questionário avaliativo (QA1) a cada um dos estudantes, que continha sete perguntas abertas e fechadas (Tabela 1).

Tabela 1 - Questionário avaliativo (QA1) do vídeo aplicado a turma de Ciências Naturais Perguntas

Alternativas de Resposta
1) Qual a sua avaliação do vídeo educativo a) ruim; b) fraco; c) bom; d) muito bom; e) sobre clonagem: excelente
2) Você acha que o vídeo educativo auxiliou a) sim; b) não na solução de dúvidas:
3) Na sua opinião a inclusão de vídeos educativos no ensino tem resultados positivos ou negativos? Justifique? didático para aprimorar suas aulas de ciências?
4) Você utilizaria o vídeo como material
5) Para falar sobre clonagem, o tempo do vídeo foi:
a) sim; b) não
6) $O$ objetivo do vídeo em fazer com que os alunos entendam o que é clonagem foi alcançado:
a) suficiente; b) curto; c) longo; d) insuficiente
a) sim; b) não
7) Você tem algo a sugerir para melhorar o vídeo?

Na primeira avaliação do vídeo, os alunos sugeriram apenas pequenos ajustes, como melhorias no áudio, qualidade da filmagem e adição de algumas imagens, como o nome da equipe técnica ao final do vídeo, e uma abertura com o tema. As sugestões foram atendidas com a filmagem de outro vídeo, utilizando um tablet Samsung Galaxy Note 10.1. 
Após as adequações solicitadas, o vídeo foi exibido aos trinta e sete (37) alunos do 9o ano, da Escola de EF Martinho Motta da Silveira. O vídeo foi avaliado em dois momentos pelos estudantes do EF. O questionário QA2 foi aplicado antes da exibição do curta (Tabela 2) e o questionário QA3 após sua exibição (Tabela 3). Logo após a aplicação do QA2 houve um momento de explanação sobre os conceitos que seriam abordados no vídeo, e em seguida, o curta metragem foi exibido.

Tabela 2 - Questionário da avaliação (QA2) do vídeo aplicado aos alunos do EF antes de sua exibição

Perguntas

1) Você já ouviu falar em clonagem?

2) O que você sabe sobre clonagem?

3) Você acha o assunto difícil?

4) Onde você ouviu falar sobre o assunto?

5) O que você gostaria de saber sobre esse assunto?

\section{Alternativas de Resposta}

Tabela 3 - Questionário da avaliação (QA3) do vídeo aplicado aos alunos do EF após sua exibição Perguntas

a) sim; b) não

a) sala de aula; b) TV; c) revista; d) jornal;

e) internet; f) outro

\footnotetext{
1) Qual a sua avaliação do vídeo sobre clonagem?

2) Você acha que o vídeo educativo, como foi apresentado, auxiliou a solucionar dúvidas?

3) Qual a sua opinião sobre vídeos educativos no ensino de ciências? Eles são utilizados por seus professores?
}

Alternativas de Resposta

4) O objetivo em fazer com que os alunos

a) sim; b) não entendam o que é clonagem foi alcançado?

a) ruim; b) fraco; c) bom; d) muito bom; e) excelente

a) sim; b) não.

5) O que mais te chamou atenção no vídeo?

A presente pesquisa respeitou os princípios elencados pela Resolução № 510 , que regulamenta a pesquisa com seres humanos no país. Mediante o aceite em fazer parte do estudo, e a fim de garantir o sigilo e o anonimato dos participantes, foram encaminhados aos alunos do ES os Termos de Consentimento Livre e Esclarecido (TCLE) para conhecimento e autorização da participação.

A pesquisa foi apresentada ao Diretor da Escola de EF, que concordou com a exibição do vídeo aos alunos. Para explicitar a concordância dos alunos em fazer parte do estudo foram encaminhados, aos seus respectivos responsáveis, os Termos de Consentimento Livre e Esclarecido (TCLE) para conhecimento e autorização da participação dos adolescentes na 
pesquisa, bem como, fora apresentado aos alunos os Termos de Assentimento Livre e Esclarecido (TALE), a fim de garantir consentimento, o sigilo e o anonimato dos participantes.

\section{Resultados e discussão}

O vídeo apresentado aos alunos do ES e EF abordava a temática de Clonagem, trazendo no roteiro informações técnico-científicas das questões mais relevantes, e que causam as principais indagações. O vídeo continha recursos audiovisuais como: músicas, animações, imagens e simulações, que despertaram a atenção dos alunos, auxiliando na compreensão e assimilação do conteúdo abordado, apresentado de forma clara, concisa e descontraída. O vídeo foi produzido a baixo custo e com equipamento habitualmente disponível no cotidiano, sendo facilmente reprodutível com os mais diversos temas.

A maioria dos universitários que participou da pesquisa considerou a duração do vídeo suficiente para abordar o tema clonagem. Todavia um terço dos entrevistados achou a exibição curta. Este posicionamento sobre o tempo de exibição pode estar associado a forma divertida e lúdica que o assunto foi apresentado, fazendo com que os alunos desejassem mais momentos de distração e discussão, bem como, a ansiedade para ampliação do debate. Além disso, o público em questão era composto por estudantes universitários, que sugeriram uma abordagem mais extensa do assunto, baseado em suas próprias indagações sobre o tema.

Os licenciados do curso de Ciências Naturais, espectadores da primeira exibição do vídeo, expressaram que utilizariam o material educativo para aprimorar suas futuras aulas de ciências, acreditando que teriam resultados positivos. Também foi relatado que o vídeo despertaria o interesse e atenção dos estudantes do $\mathrm{EF}$, pois a aula fica mais interessante, dinâmica e divertida, permitindo clareza no entendimento do assunto abordado, ajudando a esclarecer dúvidas, de maneira imediata. Vale ressaltar que o vídeo continha temas atuais de biotecnologia, tendo em vista a contemporaneidade tecnológica em que vivemos e a formação docente dos futuros professores de Ciências.

O ensino dito tradicional possui eficiências e especificidades em todos os estágios no processo de aprendizagem, todavia, as novas tecnologias podem e devem ser implantadas, incrementando ainda mais a forma de ensinar e permitindo uma maior intimidade entre docente, estudante e conhecimento proposto. Portanto, é importante que o docente esteja sempre atualizado, tanto no que se refere aos conteúdos, quanto às tecnologias e pedagogias atuais (FORMIGA et al., 2017).

Schneider, Meglhioratti; Corazza (2016) afirmam que é importante levar temas de ampla relevância social e divulgação para cursos de formação continuada para estimular a reflexão dos professores, uma vez que estes são os responsáveis por formar cidadãos conscientes, críticos e éticos para atuar em sociedade.

Atualmente o número de descobertas científicas aumenta a cada dia e muitas dessas descobertas englobam o campo da biologia. Diante disso, os professores de biologia e de disciplinas correlatas devem estar em constante atualização e sincronia com toda essa dinâmica científica. Some-se a isso, as metodologias que os professores irão utilizar na sua prática docente, o que possibilita determinar o aprendizado do estudante de forma significativa, sem o 
mecanicismo dos conteúdos decorados, que são esquecidos após as avaliações (SILVA-JUNIOR; BARBOSA, 2009).

A anuência dos alunos do curso de Ciências Naturais para a utilização do vídeo, como ferramenta pedagógica, afirmando que aquele formato de produção auxilia na solução de dúvidas sobre o tema escolhido, motivou a exibição aos alunos do EF. A utilização de recursos didáticos torna as aulas mais dinâmicas, possibilitando que os alunos compreendam melhor os conteúdos, deixando-os motivados e envolvidos com o tema que está sendo discutido, proporcionando, assim, uma melhor compreensão e interpretação do que está sendo trabalhado (NICOLA; PANIZ, 2016). Segundo Silva, Pereira; Arroio (2017) o uso de vídeos como recurso didático permite que o docente explore o conteúdo em aula de forma atrativa e divertida, por meio de imagens e sons que possivelmente chamará e prenderá a atenção dos estudantes.

Após a incorporação das sugestões feitas pelos discentes do ES, o vídeo foi exibido aos alunos do 9o ano da Escola de EF Martinho Motta da Silveira. Primeiramente houve a aplicação do QA2, para conhecer os conceitos prévios que os alunos apresentavam sobre clonagem. Logo que os alunos responderam ao questionário, foi apresentada uma explanação breve sobre 0 assunto em questão. Apesar de vídeos com esse teor serem, na sua maioria autoexplicativos, a presença e mediação do docente não pode ser dispensada, pois este recurso não substitui sua presença em sala de aula (OLIVEIRA; DIAS JÚNIOR, 2012).

Entre os espectadores, além de estudantes, estavam presentes representantes administrativos e pedagógicos da Escola e professores. Após a exibição, por conta da reação dos espectadores, detectou-se que o filme foi instigante e motivador à plateia, e que os alunos já detinham algum conhecimento sobre o assunto. Em seguida, o instrumento QA3 foi aplicado aos alunos do EF. Desta vez o objetivo era avaliar o vídeo como ferramenta didático-pedagógica.

A análise do instrumento QA2 demonstrou que a metade dos alunos já conhecia o assunto, sendo este conhecimento adquirido, na maioria das respostas pela TV (47\%), seguido de sala de aula (21\%) e internet (16\%). Desta forma, todos os estudantes já conheciam algo sobre clonagem e foram unânimes em declarar que gostariam de obter mais informações sobre o tema.

A análise textual discursiva foi aplicada como ferramenta analítica nas respostas subjetivas dos instrumentos QA2 e QA3. Esta abordagem de análise de dados transita entre duas formas consagradas de análise na pesquisa qualitativa, que são a análise de conteúdo e a análise de discurso (MORAES; GALIAZZI, 2007). Com o crescente uso das análises textuais nas pesquisas qualitativas, por meio de textos pré-existentes, ou produzidos a partir de entrevistas e observações, a pesquisa qualitativa pretende aprofundar a compreensão dos fenômenos que investiga a partir de uma análise rigorosa e criteriosa desse tipo de informação, isto é, não pretende testar hipóteses para comprová-las ou refutá-las ao final da pesquisa; apenas compreender os fatos observados (MORAES, 2003).

A análise textual discursiva, por outro lado, consiste em um processo em que a interpretação realizada pelos pesquisadores carrega em si uma subjetividade, a qual envolve as concepções de mundo do investigador, seus discursos, ideias preconizadas, ampliadas e reelaboradas durante o processo de construção do conhecimento (MORAES; GALIAZZI, 2011). 
A análise dos instrumentos apontou que os relatos feitos pelos alunos do EF versavam sobre: o processo de clonagem, a maneira lúdica e divertida de apresentação do assunto, a clonagem reprodutiva, e as contribuições da clonagem terapêutica, que pode ser usada na cura de certas doenças. Em seu trabalho Oliveira e Dias Júnior (2012) apresentaram um vídeo educativo sobre genética básica a uma turma de graduandos em Ciências Biológicas, e após a exibição alguns discentes mencionaram que obtiveram um melhor entendimento de conteúdo a partir da visualização das imagens, que antes só observavam estáticas em livros didáticos. Os autores concluíram que o uso de tecnologias educacionais no ensino pode auxiliar na construção de conhecimentos pelo aluno, principalmente no caso de disciplinas como a Genética, que trata de conceitos muito específicos.

A análise dos instrumentos QA1, QA2 e QA3 permitiu observar que os elementos escolhidos na elaboração e composição do vídeo, como o conhecimento científico, o roteiro usado nas filmagens e a linguagem, possibilitaram a aceitação e o fácil entendimento do conteúdo que foi explorado, pois trazia uma abordagem lúdica e atraente para o nível de escolaridade dos estudantes. Esta percepção pode ser representada nas falas dos estudantes: "seria bastante legal se esse ensino fosse compartilhado através de vídeo" (aluno do EF) e "bem explicativo e solucionou minhas dúvidas sobre esse assunto tão pouco discutido" (aluno do ES).

A análise do instrumento QA3 demonstrou que o vídeo teve ótima aceitação, ajudando a minimizar as dúvidas e alcançando o objetivo, que era fazer os alunos conhecerem mais sobre clonagem. Os dados obtidos confirmam que os alunos sentem-se mais interessados e motivados nas aulas que utilizam ferramentas de multimídia. Um relato demonstra com clareza isso quando o aluno expressa: "acho muito bom, pois ajuda a entendermos melhor o assunto" (aluno do EF).

Este quadro parece estar fortemente associado ao fato de que os vídeos, devido suas peculiares características, possuem enorme facilidade em discorrer sobre temáticas científicas de modo mais claro, desde que seja observado em sua produção, a adoção de uma linguagem de fácil compreensão, associada a elementos de humor para os alunos, o que torna essa ferramenta uma alternativa viável aos educadores, de modo a promover aulas menos cansativas e mais proveitosas. Isto também foi relatado nas seguintes falas dos alunos do EF: "o que mais me chamou atenção foi a forma de falar sobre o assunto com distração e diversão"; "Muito bom, pois os alunos vão se interessar mais"; "Foi bom porque o vídeo explicou mais que eu sabia"; "Eu achei uma maneira muito boa para aprender". Relatos como os observados apontam que houve uma absorção do conteúdo apresentado, e esperamos que a aprendizagem tenha sido alcançada, pois segundo Miranda et al. (2019), a aprendizagem só atinge significância à medida que passa a integrar as concepções do aluno dotando-o de autonomia na interpretação dos fenômenos que se pretendia abordar.

Outros alunos relataram nos instrumentos que frequentariam mais as aulas se os professores usassem esse tipo de estratégia de ensino. Pesquisas científicas voltadas para Educação em Ciências em várias áreas do conhecimento, vêm sendo desenvolvidas com o propósito de investigar como temas atuais estão sendo compreendidos, e quais as metodologias de aprendizagem utilizadas no ensino destes conceitos. As práticas de ensino adotadas em muitas escolas, por vezes, podem desestimular o aluno e distanciar o ensino da sua verdadeira função, formar cidadãos conscientes (SANTOS et. al., 2017). 
A maioria dos estudantes não respondeu a questão que indagava se havia utilização de mídias pelos professores, visando o auxílio nas aulas, talvez por não entenderam a pergunta, ou tinham pressa para responder, visto que estavam dispensados após o preenchimento do questionário; ou preferiram responder apenas as questões objetivas.

Utilizar-se de novos recursos é sempre um desafio para o docente que, por muito tempo, esteve rodeado do tradicionalismo. $O$ docente precisa vencer o receio de usar as tecnologias em seu trabalho e entender que as mídias digitais podem ser implantadas no sistema de ensino, incrementando ainda mais a forma de ensinar (ROSA, 2013; FORMIGA et al., 2017).

As mídias educacionais quando trabalhadas adequadamente por professores e alunos, favorecem a aquisição de conhecimentos, pois muda a rotina do livro-quadro-giz, tornando as aulas menos cansativas, mais prazerosas, modificando a visão do aluno e despertando neles o interesse de aprender (OLIVEIRA; DIAS JUNIOR, 2012).

Os resultados da investigação apontam que o vídeo pode ser utilizado como uma ferramenta de intervenção pedagógica, para compreensão de assuntos de Ciências, aqui em específico, o que é clonagem e como o processo é realizado, bem como, solucionar dúvidas sobre clonagem terapêutica e como essa técnica pode ajudar na cura de certas doenças. Além disso, também foi externado pelos estudantes que as aulas seriam mais prazerosas e menos cansativas se vídeos fossem produzidos para discutir questões de conteúdos como esse, pois assim haveria mais assiduidade durante as aulas.

Compartilhamos do pensamento que a crescente participação de uma cultura televisual propicia aos jovens informações, saberes, valores e padrões de consumo em espaços informais e formais. Para Formiga et al. (2017) a utilização de vídeo em sala de aula permite eficácia e maior aproximação com o docente, estudante e o conhecimento em discussão, pois aproxima as realidades a partir de um contato visual, com vista conceitual e procedimental.

A mídia-educação tem o objetivo de desenvolver sistematicamente o espírito crítico e a criatividade dos sujeitos, por meio da análise e da produção de obras midiáticas. Dessa maneira, a formação escolar em mídia-educação, além de formar um sujeito, crítico, reflexivo, que entenda como se dão os processos da mídia, também possibilita a formação de profissionais educativos de mídia, ainda mais considerando os grandes avanços tecnológicos da Internet (blogs, youtube, facebook, etc) (SOUZA; SILVA, 2009; DELIBERADOR; LOPES, 2014).

A escola deve buscar inserir as tecnologias midiáticas com maior frequência, no intuito de incentivar, estimular e preparar os docentes para utilizá-las em sala, de modo que entendam que são ferramentas que fazem parte do nosso cotidiano, e para tanto cabe salientar, que deve ser administrado de modo consciente, com bom senso e sabedoria (BENTO; BELCHIOR, 2016). Nessa perspectiva, para o docente, a utilização dessas mídias promove uma resignificação e reformulação de suas práticas pedagógicas, que serão usadas em sala de aula (SILVA; MERCADO, 2010).

Reiterando, a utilização das mídias no Ensino de Ciências vislumbra melhores condições de ensino e aprendizagem não só para esse tema, mas para outros, pois a representação do conhecimento se torna mais viável e atraente, auxiliando tanto no processo de indução de novos conceitos, como na reformulação de modelos que já faziam parte da estrutura cognitiva dos estudantes (AUSUBEL; NOVAK; HANESIAN, 1980). 
As novas tecnologias, e novas mídias, surgem a cada dia e demandam um empreendimento para que as instituições educacionais saibam manuseá-las. Neste contexto, o ensino deve também sofrer avanços, adaptar-se às novas linguagens e formas de conheceraprender, assim como se tornar mais atraente, dinâmico e significativo no processo da aprendizagem dos alunos. Desta maneira, novas mídias educacionais ganham destaques, ou ainda mídias seculares ganham nova importância educacional, entre as quais estão os filmes, de curta, média e longa duração, que podem ser um poderoso instrumento de apoio ao magistério (ANACLETO; MICHEL; OTTO, 2007). Um exemplo disso foi o uso do filme "O Óleo de Lorenzo", uma produção americana de 1992, baseada em fatos reais, que permite abordar conceitos de genética (padrões de herança) e ainda como ocorre a construção do pensamento científico (MAESTRELLI; FERRARI, 2006).

Desta forma, acreditamos que a construção de saberes dos alunos, através do processo educativo em consonância com os saberes da comunicação, pode auxiliar no aprimoramento da sensibilidade destes estudantes, tornando-os mais informados, atualizados e participantes, direcionado a formação de cidadãos conscientes do exercício pleno de sua cidadania, sem esquecer do papel fundamental do mediador desse processo.

\section{Considerações finais}

Com o percurso investigativos que realizamos, e com os dados obtidos foi possível observar que tanto os estudantes de graduação em Ciências Naturais da UNIFESSPA, quanto os estudantes do Ensino Fundamental, se sentiram mais interessados e motivados após a utilização de ferramentas de multimídia principalmente pela forma lúdica que um assunto complexo mas atual foi apresentado.

Desta maneira, o vídeo produzido e exibido para públicos diferentes, universitários, gestor, professores e alunos do 9 ํ ano do Ensino Fundamental, permitiu não só a participação dos idealizadores/executores, mas também da comunidade, seja estimulando a criação de novas mídias futuramente, seja socializando e democratizando ciência e tecnologia.

Os recursos multimídias usados pelos docentes auxiliam no desenvolvimento de metodologias e nas práticas educativas em escolas que não tenham esses recursos disponíveis. Esta ferramenta pedagógica estimula o interesse dos estudantes pelas aulas de Ciências, e por assuntos dos quais eles tenham mais dificuldades. Além disso, torna-se uma alternativa viável e acessível aos docentes, que podem lançar mão deste recurso de modo a tornar as aulas mais dinâmicas, interativas e significativas, no que diz respeito aos conteúdos desenvolvidos.

\section{Referências}

ANACLETO, A.; MICHEL. S. A. e OTTO, J. Cinema e Home Vídeo Entertaintnment: o mercado da magia e a magia do mercado. 22p, 2007.

AUSUBEL, D. P.; NOVAK, J. D. e HANESIAN, H. Psicologia educacional. 2o edição. Rio de Janeiro: Interamericana, 1980. 
BENTO, L.; CELCHIOR, G. Mídia e educação: o uso das tecnologias em sala de aula. Revista de Pesquisa Interdisciplinar, v. 1, n. Esp, 2016. Disponível em: <http://dx.doi.org/10.24219/rpi.v1iEsp.98>. Acesso em: fevereiro de 2019.

BÉVORT, E.; BELLONI, M. L. Media education: concepts, history and perspectives. Educação \& Sociedade, v. 30, n. 109, p. 1081-1102, 2009. Disponível em: http://www.scielo.br/pdf/es/v30n109/v30n109a08.pdf. Acesso em: março de 2019.

CAMPBELL, K. H. S et al. Sheep cloned by nuclear transfer from a cultured cell line. Nature, v. 380, n. 6569, p. 64, 1996. Disponível em: <https://www.nature.com/articles/380064a0>. Acesso em: janeiro de 2019.

CARNEIRO, E.; FARIA, R. L.; SHUVARTZ, M. A utilização da mídia impressa no ensino de ciências: uma proposta de debate sobre o meio ambiente. Encontro Estadual de Didática e Prática de Ensino, 3, 1-9, 2009. Disponível em: <http://www2.unucseh.ueg.br/ceped/edipe/anais/Illedipe/pdfs/2_trabalhos/gt04_fisica_quim ica_biologia_ciencias/trab_gt04_a_utilizacao_da_midia_impressa_no_ensino.pdf $>$. Acesso em: Acesso em: fevereiro de 2019.

DELIBERADOR, L. M. Y.; LOPES, M. F. Mídia-educação e cidadania: relato de três experiências realizadas com crianças e jovens do Paraná (Brasil). Revista Latinoamericana de Ciencias de la Comunicación, v. 10, n. 19, 2014. Disponível em: <http://www.alaic.org/revista/index.php/alaic/article/view/521>. Acesso em: Acesso em: fevereiro de 2019.

DUDZIAK, E. A.; FERREIRA, S. M. S. P.; FERRARI, A. C. Competência Informacional e Midiática: uma revisão dos principais marcos políticos expressos por declarações e documentos. RBBD. Revista Brasileira de Biblioteconomia e Documentação, v. 13, p. 213-253, 2017. Disponível em: <https://rbbd.febab.org.br/rbbd/article/viewFile/675/577>. Acesso em: janeiro de 2019.

FORMIGA, D. O.; SCHUNEMANN, H. E. S.; SOUZA, L. S.; BROSEGUINI, M. A utilização de tecnologias da informação e comunicação como recurso didático no ensino de história. Acta Científica, v. 26, n. 1, p. 35-46, 2017.

LIU, Z. et al. Cloning of macaque monkeys by somatic cell nuclear transfer. Cell, v. 172, n. 4, p. 881-887, 2018. Disponível em: <https://www.sciencedirect.com/science/article/pii/S0092867418300576>. Acesso em: fevereiro de 2019.

MAESTRELLI, S. R. P.; FERRARI, N. O óleo de lorenzo: O uso do cinema para contextualizar o ensino de genética e discutir a construção do conhecimento científico. Genética na Escola, v.1, n.29, p. 35-39, 2006.

MIRANDA, T. G.; NETA, A. S. A.; ARAÚJO, J. S. N.; COSTA, D. R. M.; VIANA, N. J. Q.; RAMOS, A.R. Clube de Ciências: Relato de Experiencias e Impressões de alunos. In: As ciências exatas e da terra no século XXI [recurso eletrônico] volume 2 / Organizadores Júlio César Ribeiro, Carlos Antônio dos Santos. - Ponta Grossa, PR: Atena Editora, 2019.

MORAES, R. Uma tempestade de luz: a compreensão possibilitada pela análise textual discursiva. Ciência \& Educação, v.9 n.2, p.191-211, 2003. 
MORAES, R.; GALIAZZI, M. C. Análise Textual Discursiva. Ijuí:UNIJUÍ, 2007. 224p

MORAES, R.; GALIAZZI, M. C. Análise Textual Discursiva. 2ª Ed. Ijuí:UNIJUÍ, 2011. 224p

MOUSINHO, S. H. A interdisciplinaridade ao alcance de todos. Educação Pública, v.18. 2018. Disponível em: <https://educacaopublica.cederj.edu.br/artigos/18/12/a-interdisciplinaridadeao-alcance-de-todos>. Acesso em: fevereiro de 2019.

NICOLA, J. A.; PANIZ, C. M. A importância da utilização de diferentes recursos didáticos no Ensino de Ciências e Biologia. InFor, v. 2, n. 1, p. 355-381, 2016. Disponível em: $<$ https://ojs.ead.unesp.br/index.php/nead/article/view/InFor2120167>. Acesso em dezembro de 2019.

NUNES, F. M. F. Do laboratório à sala de aula: os recentes avanços da Genética. Genética na Escola, $\quad$ v. 2010.2 Disponível em: <https://www.researchgate.net/profile/Francis_Nunes/publication/308741858_Do_laboratori o_a_sala_de_aula_os_recentes_avancos_da_genetica/links/57edb98108ae07d8d8f64aab/Dolaboratorio-a-sala-de-aula-os-recentes-avancos-da-genetica.pdf.>. Acesso em dezembro de 2019.

OLIVEIRA, N. M.; DIAS JÚNIOR, W. O uso do vídeo como ferramenta de ensino aplicada em Biologia Celular. Enciclopédia Biosfera: Centro Cientifico Conhecer, v. 8, n. 14, p. 1788, 2012. Disponível em: <http://www.conhecer.org.br/enciclop/2012a/humanas/o\%20uso.pdf >. Acesso em: fevereiro de 2019.

PENHA, P. X.; MACIEL, M. D. Presença do enfoque ciência, tecnologia e sociedade nos livros didáticos de ciências do triênio 2017-2019, nos anos finais do ensino fundamental em Ouro Branco - MG. ForScience v. 9 n. 1, p. 1-22, 2021.

ROSA, R. Trabalho docente: dificuldades apontadas pelos professores no uso das tecnologias. Revista Encontro de Pesquisa em Educação, v. 1, n. 1, p. 214-227, 2013. Disponível em: <http://www.revistasdigitais.uniube.br/index.php/anais/article/view/710>. Acesso em: janeiro de 2019.

RUMPF, R.; IGUMA, L. T.; SOUSA, R. V. Produção de clones pela transferência nuclear em bovinos. Revista do Conselho Federal de Medicina Veterinária, 22, 16 - 24, 2001.

SCHNEIDER, E. M.; MEGLHIORATTI, F. A.; CORAZZA, M. J. Discursos de professores em formação continuada acerca da relação entre a manipulação genética e a possibilidade de melhoramento em humanos. Ciência \& Educação, v. 22, n. 3, p. 597-613, 2016. Disponível em: <http://www.redalyc.org/pdf/2510/251047415004.pdf>. Acesso em: dezembro de 2019.

SILVA-JUNIOR, A. N.; BARBOSA, J. R. A. Repensando o Ensino de Ciências e de Biologia na Educação Básica: o caminho para a construção do conhecimento científico e biotecnológico. Democratizar, Rio de Janeiro, v. 3, n. 1, p. 1-15, 2009. Disponível em: $<$ http://files.bioaprendizagem.webnode.com/200000004bed1ec22fb/Repensando\%20o\%20En sino\%20de\%20Ci\%C3\%AAncias\%20e\%20de\%20Biologia\%20na\%20Educa\%C3\%A7\%C3\%A30\%2 OB\%C3\%A1sica.pdf>. Acesso em: fevereiro de 2019.

SILVA, M. J.; PEREIRA, M. V.; ARROIO, A. O papel do youtube no ensino de ciências para estudantes do ensino médio. Revista de Educação, Ciências e Matemática, v. 7, n. 2, 2017. 
Disponível em: <http://publicacoes.unigranrio.edu.br/index.php/recm/article/view/4560/0>. Acesso em: fevereiro de 2019.

SILVA, R. V.; MERCADO, E. L. O. O Vídeo como recurso de aprendizagem em salas de aula do 50 ano. Revista EDaPECl, v. 6, n. 6, 93-103, 2010. Disponível em: <https://seer.ufs.br/index.php/edapeci/article/view/602/506>. Acesso em: março de 2019.

SILVA, T. J. C. Clonagem: o que aprendemos com Dolly? Ciência e Cultura, v. 56, n. 3, p. 27-30, 2004.

$<$ http://cienciaecultura.bvs.br/scielo.php?pid=S000967252004000300015\&script=sci_arttext\& tlng=pt $>$. Acesso em: fevereiro de 2019.

SOUZA, D. M.; SILVA, A. C; PIRES, G. L. Construindo diálogos em mídia-educação e Educação Física: algumas reflexões a partir de estudos do Observatório da Mídia Esportiva/UFSC. Revista Conhecimento Online, v. 1, p. 22-43, 2009. Disponível em: <http://periodicos.feevale.br/seer/index.php/revistaconhecimentoonline/article/view/10>. Acesso em: fevereiro de 2019.

TUFTE, B.; CHRISTENSEN, O. Mídia-Educação - Entre Teoria E A Prática. Perspectiva, v. 27, n.1, p. 97-11. 2009. Disponível em: <https://periodicos.ufsc.br/index.php/perspectiva/article/view/13133>. Acesso em: janeiro de 2019.

United Nations Educational, Scientific and Cultural Organization. Grünwald Declaration on Media Education. International Symposium on Media Education, Grünwald, Federal Republic of Germany. 1982. Disponível em: <http://www.unesco.org/education/pdf/MEDIA_E.PDF>. Acesso em: fevereiro de 2019.

ZATZ, M. Clonagem humana: conhecer para opinar. Pesquisa Fapesp, v. 73, p. 8-14, 2002. Disponivel em: <http://www.revistapesquisa.fapesp.br/wpcontent/uploads/2002/03/08_PERGUNTASF.pdf>. Acesso em: março de 2019.

ZATZ, M. Clonagem e células-tronco. Estudos avançados, v. 18, n. 51, p. 247-256, 2004. Disponível em: <http://cienciaecultura.bvs.br/pdf/cic/v56n3/a14v56n3.pdf.>. Acesso em: março de 2019. 